\title{
New Treatment in Facial Nerve Palsy Caused by Sagittal Split Ramus Osteotomy of Mandible
}

Jin Hoon Lee, Kyung Ah Lee

Department of Plastic and Reconstructive Surgery, Haeundae Paik Hospital, Inje University College of Medicine, Busan, Korea

No potential conflict of interest relevant to this article was reported.

\begin{abstract}
A 25-years-old woman with mandibular prognathism underwent a mandibular setback by way of mandibular sagittal split ramus osteotomy (MSSRO). After 2 days of operation, she developed difficulty of closing her right eye. The blink reflex test and motor nerve conduction study of the right orbicularis oris muscle were revealed right facial neuropathy of unknown origin and House-Brackmann facial nerve grading system (HBFNGS) grade V. For treatment, we initially prescribed oral prednisolone and nimodipine including physical therapy. The samples consisted of 11 facial nerve palsy patients caused by MSSRO and were analysed about onset of facial nerve palsy, postoperative HBFNGS, final HBFNGS, treatment method and recovery time. At 10 weeks of treatment of nimodipine, she had completely regained normal function (HBFNGS grade I) of the right facial nerve. The clinical results lead to assume a fast recovery of facial nerve function by the nimodipine medication, whereas average time of recovery is 16.32 weeks in references. Despite of the limited one patient treated, the result was very promising with respect to a faster recovery of the facial nerve function. Considering the use of nimodipine treatment for peripheral facial nerve palsy following a surgical approach with an anatomically preserved nerve can be recommended.
\end{abstract}

Keywords: Osteotomy, sagittal split ramus / Facial paralysis / Nimodipine

\section{INTRODUCTION}

Mandibular sagittal split ramus osteotomy (MSSRO) can be used as a corrective procedure for malocclusion, facial asymmetry, and mandibular deformities, including mandibular prognathism and retrognathism [1]. However, various complications may occur following MSSRO, including inferior alveolar nerve damage, bleeding, condylar displacement, condylar dysfunction, unwanted secondary fractures, skeletal regression, and facial nerve palsy (FNP). FNP has been reported in $0.17 \%$ to $0.75 \%$ of cases; direct causes include intraoperative injury to the facial nerve, postoperative edema, and positional change in the styloid process; indirect inju-

\section{Correspondence: Kyung Ah Lee}

Department of Plastic and Reconstructive Surgery, Haeundae Paik Hospital, Inje University College of Medicine, 875 Haeun-daero, Haeundae-gu, Busan 48108, Korea

E-mail: dlruddk01@naver.com

Received December 15, 2016 / Revised March 11, 2017 / Accepted March 12, 2017 ry can occur from retraction or excessive posterior tissue traction on the mandibular ramus [2-5]. The severity of FNP after facial nerve damage and the speed of recovery may vary according to the mechanism of injury, but most FNP cases due to indirect causes are considered [3].

To increase the speed of recovery from FNP, available methods include physical therapy, using transdermal nerve stimulation and electro-acupuncture, and drug therapy, using steroids and anti-inflammatory agents. However, as reported by Cai et al. [6] concomitant treatment with drug and physical therapies required an average of 28.8 weeks for complete recovery of FNP, while treatment using drug therapy alone required an average of 39.2 weeks; therefore, conventional drug therapy was unable to significantly increase the speed of facial nerve recovery [7].

Accordingly, the authors of the present study examined recovery in post-MSSRO patients with FNP who were prescribed ni- 
modipine (Nimotop $30 \mathrm{mg}$ Tablets, Bayer AG, Germany), a calcium antagonist vasodilator, and compared the results to literature reports on recovery in patients who did not use nimodipine; the patients treated with nimodipine showed slightly faster recovery [4,8-13].

\section{CASE REPORT}

A 25-year-old female was admitted with mandibular prognathism, class III malocclusion, and macrogenia (Fig. 1). The patient underwent MSSRO under general anesthesia. A side cutter was used for the surgery, which involved direct retraction of the mandibular foramen by performing horizontal osteotomy on the inside of the ramus, followed by sagittal splitting using a reciprocating saw and osteotome. The distal bone fragment was retracted by $9 \mathrm{~mm}$, and fixation was performed to match the new occlusal surface. There were no specific findings during surgery and postoperative bleeding and swelling were not excessive. Immediately after surgery, there was no noticeable difference in the movement of the facial muscles, but by postoperative day (POD) 2, the patient had difficulty closing her right eye completely, weakness on wrinkling the forehead, and deviation to the left side when protruding her tongue. To record the progression of symptoms, photos were taken with the consent of the patient, and the clinical features including facial expression were recorded according to grade $\mathrm{V}$ in the House-Brackmann facial nerve grading system (HBFNGS) (Figs. 2, 3A, C). To determine the cause, X-ray imaging was performed; the results showed no direct pressure from retraction of the mandibular ramus or any other specific findings that would require additional surgery, such as mandibular condylar fracture. Thus, temporary FNP due to indirect pressure on the facial nerve from mild hematoma and edema was diagnosed (Fig. 4). Nerve conduction and blink reflex tests were performed and the patient was diagnosed with right FNP injury without the loss of nerve continuity (Fig. 5). To treat the FNP, drug therapy using steroids (prednisolone), anti-inflammatory agents, and nimodipine was administered, and concomitant physical therapy using transdermal nerve stimulation and electro-acupuncture therapies was performed. Prednisolone $15 \mathrm{mg}$ three times a day (tid) was ad- ministered for 4 weeks, followed by $10 \mathrm{mg}$ tid for 4 weeks, then 5 $\mathrm{mg}$ tid for an additional 2 weeks. Nimodipine $30 \mathrm{mg}$ tid was administered for 4 weeks. Steroids, physical therapy, and nimodipine were administered; starting 2 weeks after treatment began, the patient recovered to HBFNGS grade III, and was able to close her right eye. Subsequently, she recovered to HBFNGS grade II by 8 weeks, and HBFNGS grade I by 10 weeks, with eventual complete recovery (Figs. 3B, D, 4, 6).

To compare the recovery speed with that reported in reference articles on post-MSSRO FNP occurred in 11 patients who re-

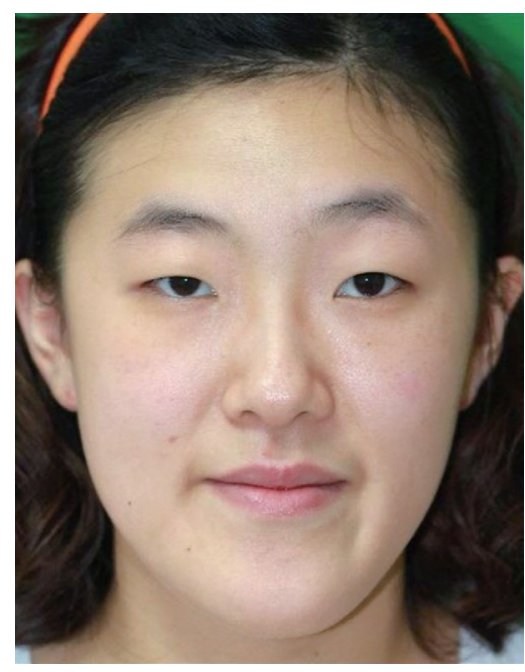

Fig. 1. Preoperative frontal view.

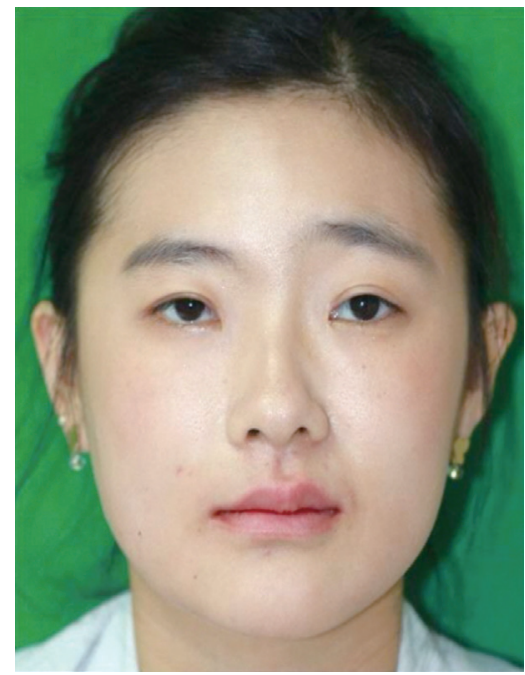

Fig. 2. Frontal view of postoperative 10 days at rest. Both eyebrow height and shape of nasolabial folds are asymmetry. 

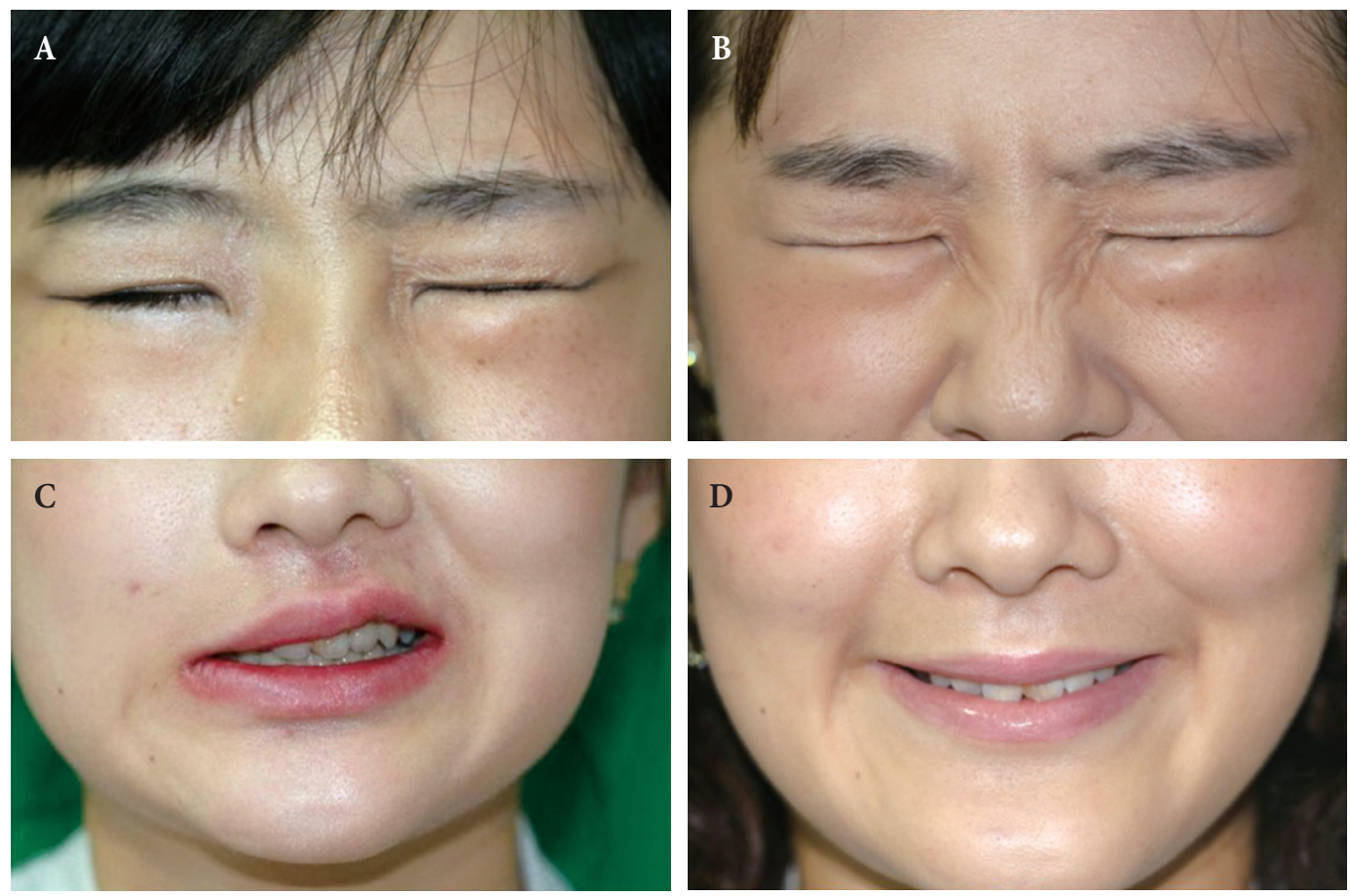

Fig. 3. (A, C) At postoperative 10 days, the photographs are showing right facial muscles completely paralyzed. (B, D) At postoperative 10 weeks, the photographs are normal facial expression regained.

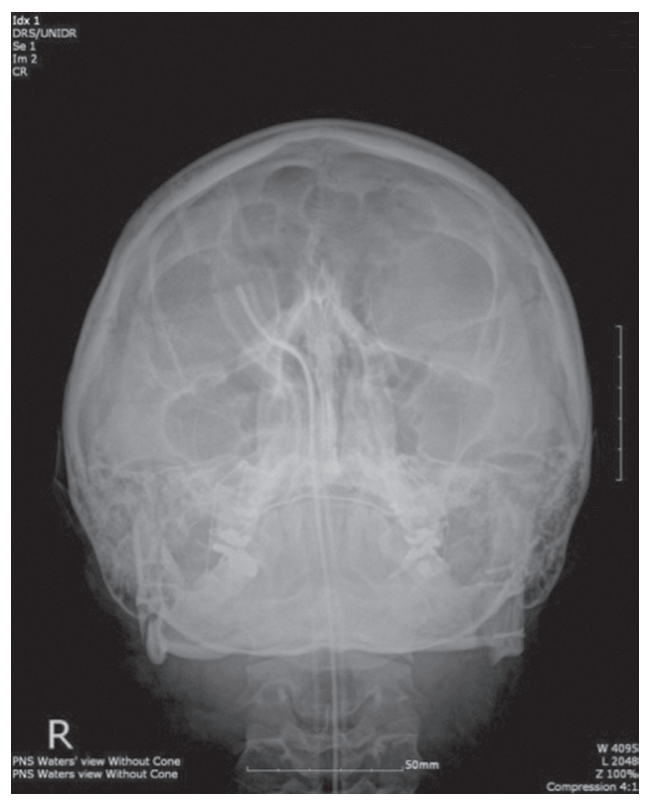

Fig. 4. The postoperative X-ray shows well adapted both segmental bones without any other unfavorable fracture of mandible.

ceived steroid administration and physical therapy, but not nimodipine, the present study analyzed the onset of FNP, HBFNGS at the time of initial diagnosis, HBFNGS after recovery, treatment method, and the time to recovery. In the reference articles, the time of onset varying from POD 1 to POD 6; in 9 of the 11 (81.8\%), FNP appeared by POD 3. At the time of diagnosis, the severity was HBFNGS grade IV-V in all cases. The use of drug therapy except nimodipine, combined with physical therapy, showed no major difference, with an average recovery time of 16.32 weeks. The recovery time of 10 weeks in the present study was slightly faster (Table 1) [4,10-14]. Moreover, there were no complications from nimodipine administration.

\section{DISCUSSION}

MSSRO is in wide use for mandibular prognathism, but FNP caused by this procedure is known to be rare. de Vries et al. [2] reported 9 cases (0.52\%) of FNP among 1,747 patients who underwent MSSRO, while Behrman [15] reported FNP in only 4 patients $(0.67 \%)$ among 600.

Although the exact mechanism has not been identified, Dendy [3] suggested 3 possibilities for post-MSSRO FNP: pressure from 
Blink Reflex

\begin{tabular}{|l|r|r|}
\hline \multicolumn{1}{|c|}{ Nerve/ Sites } & \multicolumn{1}{|c|}{$\begin{array}{l}\text { R1 } \\
\mathrm{ms}\end{array}$} & \multicolumn{1}{|c|}{$\begin{array}{l}\text { R2 } \\
\mathrm{ms}\end{array}$} \\
\hline L. SUPRAORBITAL & \multicolumn{3}{|l|}{} \\
\hline 1. Ipsi & 11.15 & 37.80 \\
\hline 2. Cont & & No \\
\hline R SUPRAORBITAL & \multicolumn{1}{|l}{} \\
\hline 1. Ipsi & No & \\
\hline 2. Cont & & 37.75 \\
\hline
\end{tabular}

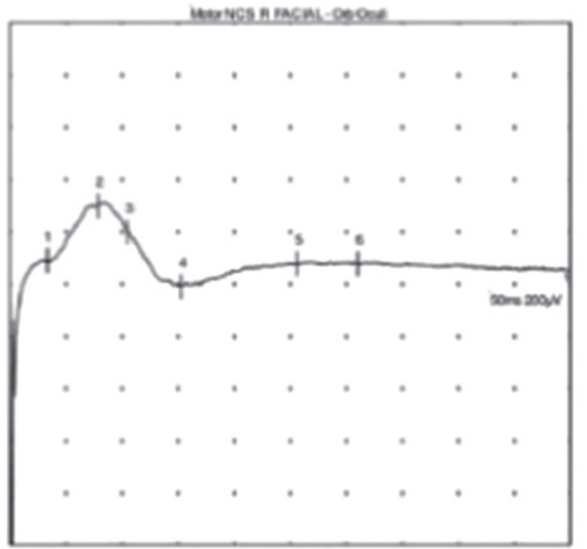

Motor NCS

\begin{tabular}{|l|r|r|r|}
\hline \multicolumn{1}{|c|}{ Nerve / Sites } & $\begin{array}{c}\text { Latency } \\
\mathrm{ms}\end{array}$ & $\begin{array}{c}\text { Amp.2-4 } \\
\mathrm{mV}\end{array}$ & Segments \\
\hline R FACLA - Orb Oculi \\
\hline 1. Ant Ear & 3.35 & 0.3 & 1 - 0 \\
\hline L FACLAL - Orb Oculi & \multicolumn{3}{|l|}{} \\
\hline 1. Ant Ear & 2.85 & 0.8 & 1 - 0 \\
\hline
\end{tabular}

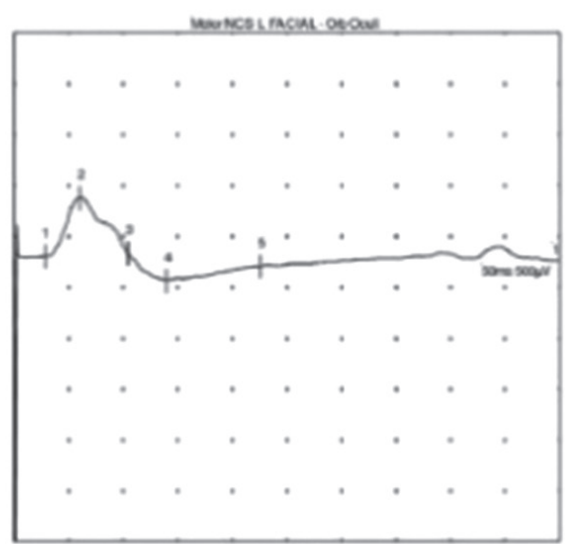

Fig. 5. Blink reflex and motor nerve conduction study. Facial nerve stimulation showed a small amplitude response on the right side as compared to the left. Nerve conduction study showed no denervation (probably too early after onset). There is electrophysiological evidance of dysfunction in the bilateral blink test and motor nerve conduction study. Findings are consistent with a right facial palsy with axonal changes with nerve continuity.

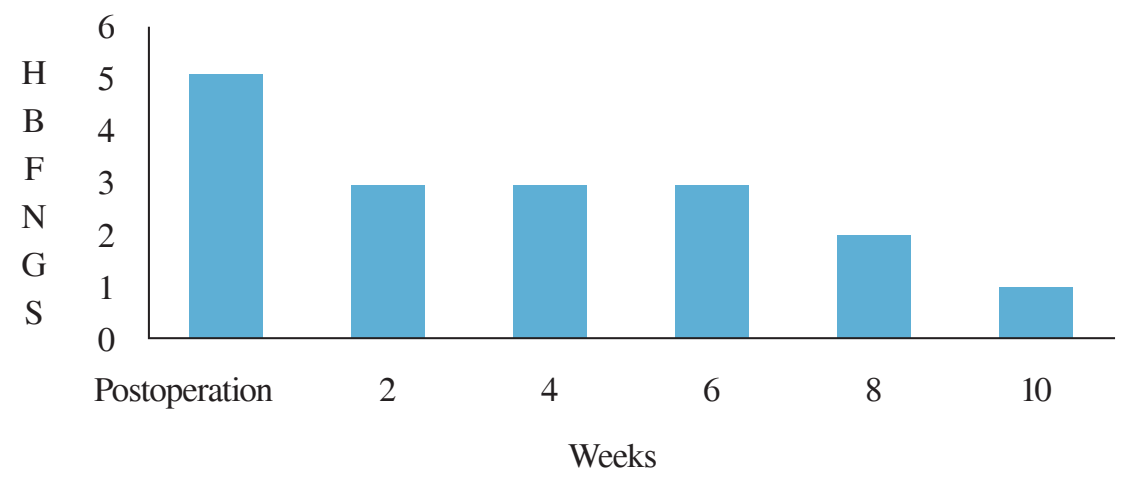

Fig. 6. Graph of facial nerve recovery. There was a significant recovery of the facial nerve function after 2 weeks of nimodipine treatment. At 8 weeks, recovery of facial nerve function was found to HBFNGS 2. At 10 weeks, HBFNGS 1 (normal grade) of the facial nerve functions was seen. HBFNGS, House-Brackmann facial nerve grading system.

use of a retractor on the posterior mandibular ramus, posterior deviation of the bone fragment of the styloid process, and direct pressure from retraction of the distal segment. Jones and Van Sickels [5] also reported a similar mechanism, in which formation of postoperative hematoma was said to support the causes reported by Dendy [3]. In the present case, the mandibular retractor was used to the same degree on both sides during the procedure and radiologic findings showed no direct pressure from retraction of the distal segment or additional fracture in the mandible. Moreover, since the nerve conduction and blink reflex tests showed no indication of a severe nerve, it is believed that FNP symptoms were temporary, and due to postoperative hematoma exerting in- 
Table 1. Transient facial palsy after bilateral sagittal split osteotomy of mandible in author's case and reference cases

\begin{tabular}{|c|c|c|c|c|c|c|c|c|}
\hline \multirow[b]{2}{*}{ No. [references] } & \multirow{2}{*}{$\begin{array}{l}\text { Onset of } \\
\text { palsy (day) }\end{array}$} & \multirow{2}{*}{$\begin{array}{c}\text { Postoperative } \\
\text { HBFNGS }\end{array}$} & \multirow{2}{*}{$\begin{array}{c}\text { Final } \\
\text { HBFNGS }\end{array}$} & \multicolumn{4}{|c|}{ Treatment } & \multirow{2}{*}{$\begin{array}{l}\text { Recovery } \\
\text { time (wk) }\end{array}$} \\
\hline & & & & $\begin{array}{c}\text { Facial } \\
\text { nerve training }\end{array}$ & $\begin{array}{c}\text { Vitamins } \\
\text { B1, B6, B12 }\end{array}$ & Steroid & $\begin{array}{l}\text { Nimo- } \\
\text { dipine }\end{array}$ & \\
\hline Author's case & 2 & 5 & 1 & + & & + & + & 10 \\
\hline $1[4]$ & 2 & 4 & 1 & + & + & & & 12 \\
\hline 2 [10] & 3 & 5 & 1 & + & + & + & & 24 \\
\hline $3[11]$ & 1 & 5 & 1 & + & & + & & 12 \\
\hline 4 [12] & 3 & 5 & 1 & + & & + & & 24 \\
\hline $5[12]$ & 6 & 5 & 1 & + & & + & & 12 \\
\hline 6 [12] & 1 & 5 & 1 & & & + & & 24 \\
\hline 7 [12] & 3 & 5 & 1 & + & & + & & 16 \\
\hline 8 [13] & 3 & 4 & 1 & + & & + & & 12 \\
\hline 9 [14] & 4 & 5 & 1 & + & & + & & 12 \\
\hline $10[14]$ & 1 & 4 & 1 & + & & + & & 12 \\
\hline $11[14]$ & 1 & 5 & 1 & + & & + & & 16 \\
\hline
\end{tabular}

HBFNGS, House-Brackmann facial nerve grading system.

direct pressure. Because it was believed that the symptoms were caused by local ischemia due to interruption of circulation to the facial nerve by hematoma, the present case used a vasodilator, nimodipine, to enhance the recovery speed.

To describe the severity of nerve injury is the HBFNGS, which classifies FNP according to clinical features of facial expression with muscles at rest and active. In Grade I, normal function is possible. Grade II represents mild dysfunction, with slight weakness noticeable upon close inspection. Grade III represents moderate dysfunction, with noticeable weakness but no aesthetic asymmetry or dysfunction during movement. Grade IV represents moderately severe dysfunction and obvious weakness, with disfiguring asymmetry during function and normal symmetry at reset. Grade V represents severe dysfunction, with asymmetry even at rest and only barely perceptible motion. Grade VI represents total paralysis, with absence of movement [16]. This classification system can be used to evaluate the level of recovery. The FNP symptoms that appeared on POD 2 in the present case corresponded to grade $\mathrm{V}$.

There are many treatment modalities available for FNP. Physical therapy and use of steroids and anti-inflammatory agents have been tried, with many clinical trials reported. However, methods to shorten the recovery time have not been reported [7].

Nimodipine is a 1,4-dihydropyridine derivative and a potent antagonist of voltage gated L-type Ca2p-ion channels. It has high lipid affinity and selective cerebral vasodilation function. This inhibits calcium ions from entering voltage-sensitive sites in neurons and smooth muscle cells to provide protection from neural swelling caused by calcium overload [8]. Strauss et al. [17] reported that when nimodipine was used during acoustic neuroma surgery, most patients showed no diminished function in their acoustic and facial nerves. Angelov et al. [18] reported positive effects of nimodipine in posttraumatic facial nerve recovery in an animal experiment. In the group that received nimodipine, severed facial nerves were reconnected in 14-28 days with restored function. Scheller et al. $[9,19]$ reported that use of nimodipine after acoustic neuroma surgery had had a neural protective function for prevention of FNP. When nimodipine was discontinued after 10 days, symptoms of FNP reappeared in all 7 patients within 2-5 days; when nimodipine was resumed, facial nerve function again recovered. Based on these results, our hospital administered nimodipine in a patient who exhibited symptoms of FNP following MSSRO, and recovery from HBFNGS grade V to grade I was achieved within 10 weeks. Although the present case involved only 1 patient, compared to an average recovery time of 16.32 weeks (3-6 months) reported for other FNP patients, the speed of functional recovery by the facial nerve in the present case was slightly faster [5,11-13,20]. 
Nimodipine can be tried when an injured facial nerve still has anatomical continuity. Unlike conventional methods that use steroids alone, we administered a combination of prednisolone and nimodipine with concomitant physical therapy. The patient with FNP received a gradually decreasing dosage of prednisolone for 10 weeks and $30 \mathrm{mg}$ of nimodipine three times a day for the first 4 weeks. If the efficacy of nimodipine can be proven through study of a larger number of cases without serious complications, then nimodipine can be used to accelerate the recovery process in postoperative FNP.

\section{REFERENCES}

1. Martis CS. Complications after mandibular sagittal split osteotomy. J Oral Maxillofac Surg 1984;42:101-7.

2. de Vries K, Devriese PP, Hovinga J, van den Akker HP. Facial palsy after sagittal split osteotomies: a survey of 1747 sagittal split osteotomies. JCraniomaxillofac Surg 1993;21:50-3.

3. Dendy RA. Facial nerve paralysis following sagittal split mandibular osteotomy: a case report. Br J Oral Surg 1973;11:101-5.

4. Sakashita H, Miyata M, Miyamoto H, Miyaji Y. Peripheral facial palsy after sagittal split ramus osteotomy for setback of the mandible: a case report. Int J Oral Maxillofac Surg 1996;25:182-3.

5. Jones JK, Van Sickels JE. Facial nerve injuries associated with orthognathic surgery: a review of incidence and management. J Oral Maxillofac Surg 1991;49:740-4.

6. Cai ZG, Shi XJ, Lu XG, Yang ZH, Yu GY. Efficacy of functional training of the facial muscles for treatment of incomplete peripheral facial nerve injury. Chin J Dent Res 2010;13:37-43.

7. Lee KJ, Fee WE Jr, Terris DJ. The efficacy of corticosteroids in postparotidectomy facial nerve paresis. Laryngoscope 2002;112:1958-63.

8. Mattsson P, Janson AM, Aldskogius H, Svensson M. Nimodipine promotes regeneration and functional recovery after intracranial facial nerve crush. J Comp Neurol 2001;437:106-17.
9. Scheller C, Richter HP, Engelhardt M, Koenig R, Antoniadis G. The influence of prophylactic vasoactive treatment on cochlear and facial nerve functions after vestibular schwannoma surgery: a prospective and open-label randomized pilot study. Neurosurgery 2007;61:92-7.

10. Ruiz LP, Lara JC. Facial nerve palsy following bilateral sagittal split ramus osteotomy for setback of the mandible. Int J Oral Maxillofac Surg 2011;40:884-6.

11. Baek RM, Song YT. Transient total facial palsy after bilateral sagittal split ramus osteotomy. Plast Reconstr Surg 2004;113:1730-3.

12. Choi BK, Goh RC, Chen PK, Chuang DC, Lo LJ, Chen YR. Facial nerve palsy after sagittal split ramus osteotomy of the mandible: mechanism and outcomes. J Oral Maxillofac Surg 2010;68:1615-21.

13. Rai KK, Shivakumar HR, Sonar MD. Transient facial nerve palsy following bilateral sagittal split ramus osteotomy for setback of the mandible: a review of incidence and management. J Oral Maxillofac Surg 2008:66:373-8.

14. Koh KM, Yang JY, Leem DH, Baek JA, Ko SO, Shin HK. Facial nerve palsy after sagittal split ramus osteotomy: follow up with electrodiagnostic tests. J Korean Assoc Maxillofac Plast Reconstr Surg 2011;33:190-7.

15. Behrman SJ. Complications of sagittal osteotomy of the mandibular ramus. J Oral Surg 1972;30:554-61.

16. Yen TL, Driscoll CL, Lalwani AK. Significance of House-Brackmann facial nerve grading global score in the setting of differential facial nerve function. Otol Neurotol 2003;24:118-22.

17. Strauss C, Bischoff B, Neu M, Berg M, Fahlbusch R, Romstock J. Vasoactive treatment for hearing preservation in acoustic neuroma surgery. J Neurosurg 2001;95:771-7.

18. Angelov DN, Neiss WF, Streppel M, Andermahr J, Mader K, Stennert E. Nimodipine accelerates axonal sprouting after surgical repair of rat facial nerve. J Neurosci 1996;16:1041-8.

19. Scheller C, Strauss C, Fahlbusch R, Romstock J. Delayed facial nerve paresis following acoustic neuroma resection and postoperative vasoactive treatment. Zentralbl Neurochir 2004;65:103-7.

20. O’Regan B, Bharadwaj G. Comparison of facial nerve injury and recovery rates after antegrade and retrograde nerve dissection in parotid surgery for benign disease: prospective study over 4 years. Br J Oral Maxillofac Surg 2011;49:286-91. 